\title{
El Sistema de la ciencia: \\ la filosofía no disyuntivista de Hegel ${ }^{*}$
}

Fecha de entrega: 18 de abril de 2019

Fecha de evaluación: 28 de junio de 2019

Fecha de aprobación: 30 de septiembre de 2019

Juan Camilo Hernández Rodríguez

\section{Resumen}

En este texto me propongo elaborar un esbozo general de los principales conceptos clave del Sistema de la ciencia de Hegel: el Absoluto, la determinación, la distinción entre realidad, existencia y ser, y la relación entre lo finito e infinito. Mi propósito en este texto es ofrecer los rasgos fundamentales del sistema metafísico hegeliano a partir de su contexto previo, de su obra y de una lectura de bicondicionalidad $-\mathrm{y}$ no de identidad - de dichos conceptos, relaciones y estructuras como no-disyuntivistas. Finalmente, a partir de dicha exposición evaluaré si las principales críticas que se le han hecho a Hegel son o no justificadas y si son o no un problema serio para su proyecto metafísico: el Sistema de la ciencia.

Palabras clave: Sistema de la ciencia, espíritu, realidad [Wirklichkeit], Absoluto, finito-infinito.

* Este trabajo corresponde a los intereses investigativos del licenciado Hernández, quien se ha preocupado por la filosofía analítica y del lenguaje como de la ontología y la metafísica. Es por ello que esta investigación se concentrará en el sistema de la ciencia de Hegel, específicamente en su metafísica.

Citar como: Hernández Rodríguez, J. C. (2020). El Sistema de la ciencia: la filosofía no disyuntivista de Hegel. Cuadernos de Filosofía Latinoamericana, 41(122), 205-234.

DoI: https://doi.org/10.15332/25005375/5533

* Juan Camilo Hernández Rodríguez es licenciado en Filosofía de la Universidad Pedagógica Nacional, Bogotá, Colombia. ORCID: http://orcid.org/0000-0001-6675-3636

Correo electrónico: IfI_jchernandezr540@pedagogica.edu.co 


\section{The System of Science: Hegel's Non-Disjuntivist Philosophy}

\section{Abstract}

This paper aims at sketching a brief exposition on key concepts from Hegel's System of Science: the Absolute; determination; the distinction between reality, existence, and being; and, finally, the relation between the finite and the infinite. To sum it up, our purpose in this text is to offer the fundamental features of the Hegelian metaphysical system by way of its previous context, Hegel's oeuvre, and a biconditional reading (not a reading of identity) of such concepts, relations, and structures as non-disjunctive. Finally, based on such exposition, the paper evaluates if the main criticisms of Hegel are justified or not, and if they pose a problem for his metaphysical project: the System of Science.

Keywords: System of Science, spirit, reality [Wirklichkeit], absolute, finite-infinite.

\section{Introducción}

En ningún lugar, ni en el cielo ni en la tierra, hay algo que no contenga en sí ambos, el ser y la nada.

Hegel, Wissenschaft der Logik

Desde la aparición de la Fenomenología del espíritu, múltiples críticas han surgido sobre el escabroso y áspero estilo de escritura de Georg Wilhelm Friedrich Hegel. Entre ellas, Arthur Schopenhauer afirmó:

Le resultaría imposible codiciar el aplauso de sus coetáneos a quien ha visto ensalzar durante veinte años a un Hegel, ese Calibán espiritual, como el mayor

1 Traducción de Rodolfo Mondolfo (en Hegel, 2013). El original dice: "daß es nirgend im Himmel und auf Erden Etwas gebe, was nicht beides Seyn und Nichts in sich enthielte" (p. 108). 
de los filósofos, gritando tan fuerte que sus ecos resonaron por toda Europa. Esta generación no puede seguir adjudicando coronas honoríficas: su aplauso se ha prostituido y su censura no significa nada. (Schopenhauer, 2016, pp. XX-XxI) ${ }^{2}$

A partir de esta cita se pueden vislumbrar dos aspectos: el primero, que el sistema filosófico de Hegel ha sido, quizás, uno de los que más ha tenido impacto en la historia de la filosofía “continental” (Stern, 2009, pp. 345-370), analítica (Hylton, 1999; Stern, 2009, pp. 117-208); incluso, la oriental; verbigracia la escuela de Kioto (Suares, 2011). Más aún, no es descabellada la idea según la cual Hegel es el punto de tránsito clave para comprender en gran medida a la filosofía contemporánea. Dice Rühle (2010):

Hasta hoy, ninguna corriente señera ni de la época moderna y ni siquiera de la actual podrá entenderse al margen de este pensamiento, ya sea porque lo desarrolle, ya sea que se le enfrente o porque asuma de forma implícita sus concepciones. Esto es válido tanto para las corrientes materialistas y marxistas como para el existencialismo que se inició con Kierkegaard; y también para la filosofía de Nietzsche, el pensamiento teológico del siglo xx, Heidegger, la hermenéutica, la fenomenología, la teoría crítica y los desarrollos del estructuralismo y del posestructualismo. Hasta en la filosofía analítica anglosajona, decididamente antimetafísica, emerge desde hace unos años una seria discusión de la idea hegeliana de que el lenguaje no se puede pensar con dependencia de los procesos históricos y sociales de su evolución. (p. XI)

Si bien esta tesis es provocadora, también es cierto que muchos académicos actuales estarían dispuestos a aceptar esta fuerte influencia de Hegel (afirmativa o negativa) en la filosofía contemporánea. Y es precisamente esto lo que nos lleva al segundo punto: no hay, quizás, filosofía más discutida, criticada, incluso vilipendiada que la de Hegel. Podrían clasificarse, de manera general, las críticas en estos bloques:

1. El político: el sistema idealista de Hegel no logra comprender que las transformaciones sociales se dan gracias a las condiciones materiales de los individuos y las sociedades, y no por una ley (idea) universal que los rija (Marx, 2012, p. 59).

2 La numeración corresponde a la paginación canónica al margen del libro (que indica la paginación de la edición original en alemán). En adelante, todos los autores clásicos (incluyendo a Hegel) serán citados canónicamente. 
2. El estético: la estética de Hegel, dado que solo reconoce la belleza en la expresión absoluta del espíritu humano (el arte), “[...] se pasa por alto que ese momento de la naturaleza aporta también al que lo contempla algo diferente, la consciencia del límite del dominio humano y la impotencia del afán y el trabajo universal” (Adorno, 1983, p. 98).

3. El histórico: el sistema filosófico de Hegel se caracteriza por ser eurocéntrico; excluye todo pensamiento que no cumpla con los cánones de racionalidad formal que ciertas lecturas de la historia de la filosofía promueven. En síntesis, la historia de la filosofía y la filosofía de la historia de Hegel suelen negar, ignorar y demeritar el pensamiento oriental, indígena, latinoamericano o, mejor dicho, lo no europeo (Dussel, 1995).

4. El epistemológico-antropológico: para Hegel, todo en el hombre es racional (Hegel, $2017, \S 5$ ), incluyendo la experiencia religiosa, los sentimientos, representaciones o la voluntad. Este racionalismo choca directamente con posturas voluntaristas (como la de Schopenhauer [2016] o Nietzsche [2000]), quienes sostienen que ese reduccionismo niega la vida misma y sus fuerzas volitivas (la voluntad de potencia [Wille zur Macht]) que son previas o más fundamentales que cualquier acto racional.

5. El lógico-metafísico: "La metafísica de Hegel tiene exactamente el mismo carácter lógico que este moderno sistema de metafísica [el Heideggeriano]; lo mismo añade al resto de los sistemas metafísicos, aun cuando la especie de su fraseología y con ello la especie de los errores lógicos en que incurren" (Carnap, 2009, p. 468). Los dos principales errores lógicos denunciados por la filosofía analítica respecto de la metafísica de Hegel son: (1) su oscuridad y lo confusos que son los términos que, a la larga, darían la impresión de caer en exabruptos tales como "la nada nadeante" de Heidegger (2014, p. 114), lo que implica que su filosofía no son más que sinsentidos y pseudoproblemas (como piensa Carnap); y (2) su dialéctica, según la cual tanto $\mathrm{P}$ como $\neg \mathrm{P}$ serían igualmente válidos y coexistentes en un tercer término que los sintetiza, viola el principio de no contradicción (Russell, 1966, p. 63). Y, dado que de una contradicción se sigue cualquier cosa (por principio de explosión [ex contraditione sequitur quodlibet]), "esta clase de teorización es tan absurda, que ni siquiera aquellos que respetan a Hegel intentan ya defenderla” (Russell, 1964, p. 251). 
Ahora bien, teniendo en cuenta estos dos elementos mencionados (la importancia de este sistema y sus constantes críticas), es correcto afirmar la utilidad y adecuación de realizar un análisis de los principales conceptos que Hegel elabora en su aporte, a mi juicio, más notable de la filosofía: un sistema metafísico sumamente complejo y amplio que se estructura en lo que él llamará "El Sistema de la ciencia"; este, si bien es poco conocido, sí ha rendido frutos a lo largo del siglo pasado y el actual. Pues, de reconocerse dicho sistema habría mayor cercanía a lo que el mismo autor consideraba que era su gran aporte a la filosofía y, en ese orden de ideas, el criterio para evaluar su aporte y sus críticas.

Con base en lo anterior, me propongo a continuación realizar un análisis de los principales elementos conceptuales del sistema metafísico de Hegel para ver cómo a partir de la comprensión del proyecto filosófico-metafísico que él desarrolló (el Sistema de la ciencia) es posible entender mejor esas críticas y saber si son o no atinadas; más aún, comprender el sistema permitiría valorar mejor el genuino aporte de Hegel en el campo de la metafísica. Así, pues, para realizar este ejercicio defenderé como tesis que es posible (y deseable) comprender el Sistema de la ciencia (y sus conceptos clave: Wirklichkeit, el Absoluto, la dialéctica) como una estructura fundamentada en relaciones bicondicionales y no de identidad. Para esto, tendré en cuenta en la exposición dos elementos fundamentales: (1) el sistema en cuanto tal; y (2) el método dialéctico. Así, paralelamente expondré los conceptos del Sistema de la ciencia y mostraré cómo es posible entender esas relaciones como bicondicionales, y así reconciliar la lógica clásica con las intenciones explicativas que Hegel posiblemente tuvo en su sistema. Finalmente, pondré en diálogo esta exposición para valorar o responder las críticas ya citadas.

\section{El Sistema de la ciencia: la estructura metafísica}

En primera instancia, "[e]s importante recalcar que la fenomenología no es la filosofía de Hegel" (Díaz, 2015), sino que es el Sistema de la ciencia. Dicho sistema se compone de tres momentos o áreas del saber filosófico: ciencia de la lógica, filosofía de la naturaleza y filosofía del espíritu, sintetizadas a modo de una enciclopedia de las ciencias filosóficas (de la cual podemos encontrar un título con igual nombre) ${ }^{3}$. En el primer momento se afirma al hombre "en sí" mismo [Self], sus condiciones de

3 Es importante aclarar que la Fenomenología del espiritu (1807) deja de ser parte del sistema de la ciencia a partir de la época de Heidelberg. Además, si bien tanto en la Fenomenología del espiritu, 
conocimiento del mundo y su relación fenomenológica con él; el segundo muestra al sujeto "para sí" en relación con los otros y el mundo; es decir, le muestra de manera objetiva y universal. Y, por último, el tercer momento o "ciencia filosófica” reúne a los dos anteriores (“en sí” y “para sí)”, superándolos para llegar al saber absoluto.

Según Hegel, el contenido de la filosofía — también de la religión y el arte- es absoluto como momento superior de autoconciencia, pues aquí el concepto logra sintetizarse subjetiva y objetivamente como idea, que es el máximo grado de racionalidad - $y$, por esto, de realidad - que el hombre puede alcanzar. Así, la labor de la filosofía debería radicar en lograr explicar ampliamente estos momentos y manifestaciones posibles del espíritu que, a juicio de Hegel, solo pueden ser a modo de enciclopedia sistemática. Él “[...] retorna, digo, a su proyecto enciclopédico, a la realización de su idea de una exposición de la filosofía en que se mostrase ésta en su carácter 'sistemático"” (Jiménez, 2009, p. 42). Al ser la filosofía de Hegel una enciclopedia, esta misma tiene una intención sistemática y metódica. Ambos componentes (sistema y método) se necesitan mutuamente y son (se dan) gracias a su armonía, a su "dialecticidad". Para dar un mejor trato al método, se expondrá primero el sistema y a partir de lo trabajado desde allí se podrá tener una visión más clara de lo que el método representa en y para sí. Empero, antes de adentrarse al sistema mismo, es de gran importancia tener en cuenta qué entiende él por ciencia (Wissenschaft) y por qué se habla de una Enciclopedia de las ciencias filosóficas.

\section{1. ¿Qué entiende Hegel por ciencia (Wissenschaft)?}

En este punto surge la cuestión: ¿por qué pensar la filosofía en un sistema? La respuesta a este interrogante está contenida en las anteriores consideraciones: porque la filosofía es ciencia ${ }^{4}$; más aún, es la ciencia primera que le permite a las otras complementarse con el saber especulativo de esta primera para elevar el conocimiento empírico al

como en la Ciencia de la lógica y en la Enciclopedia de las ciencias filosóficas se desarrollan algunos (o todos) de estos temas, las áreas del saber o "ciencias filosóficas" son independientes de estos.

4 Así lo expresa tajantemente Hegel (2010a): "[...] lo que hay de más excelente en la filosofia de nuestro tiempo pone su valor mismo en la cientificidad, y sólo por ella se hace valer, aunque los otros tomen las cosas de otro modo" (49). Entiéndase ciencia como todo tipo de estudio que indaga a su objeto con el fin de alcanzar postulados universales y axiomáticos; o, como lo indica su término alemán: "el saber adquirido/investigado" [voz Wissenschaft] (Waibl y Herdina, 1997, p. 345). Téngase en cuenta esto en adelante para no confundir esta idea con un positivismo en el proyecto hegeliano. 
absoluto (Hegel, 2017, $\$ 574$ ). El sistema es una condición sine qua non para que la ciencia sea rigurosa; así es como se consolida y toma su carácter de estricta, metódica y válida:

Un filosofar sin sistema no puede ser nada científico; por lo demás, porque tal modo de filosofar expresa de suyo más bien un modo subjetivo de sentir, es él contingente según su contenido. Un contenido sólo se justifica como momento del todo; fuera de éste es una suposición infundada o certeza subjetiva; muchos escritos filosóficos se limitan así a expresar solamente pareceres y opiniones. Erróneamente se entiende por sistema una filosofía con un principio limitado, distinto de otros; por el contrario, es principio de verdadera filosofía contener dentro de sí todos los principios particulares. (Hegel, 2017, §14)

Hegel entiende la ciencia como el estudio de la realidad (Wirklichkeit), pues considera que la realidad y la razón se implican ${ }^{5}$. Propone la idea de una enciclopedia porque, según se creía en la época, era aquella forma de escritura la que permitía conglomerar la mayor cantidad de conocimientos de determinadas ciencias de una manera completa e integral (universal). Esto explica por qué pensarse una Enciclopedia de las ciencias filosóficas.

Ahora bien, Hegel reconoce dos tipos de ciencias: la especulativa y la empírica o positiva. La primera es la filosófica; la segunda, las ciencias en el sentido común de la palabra. Ante la pregunta sobre la importancia de las ciencias filosóficas él responde:

La relación entre la ciencia especulativa y las otras ciencias consiste, por consiguiente, sólo en esto: no en que aquélla deje de lado el contenido empírico de éstas, sino que lo reconoce y usa; de tal modo reconoce lo universal de estas ciencias (las leyes, los géneros, etc.) que lo convierte en contenido propio y en estas categorías [de estas ciencias] introduce otras y las hace valer. La distinción se refiere únicamente, por tanto, a este cambio de categorías. (Hegel, 2017, \$9)

En este orden de ideas, para Hegel la filosofía no solo es ciencia, sino que, podría decirse, es la ciencia universal o ciencia de ciencias porque posee el saber especulativo. Es

5 Cabe recordar que también para los griegos una de las formas o modos de ser es "ser verdadero" (Lydell

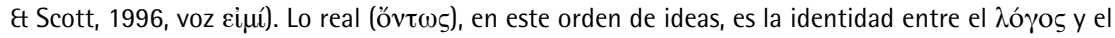

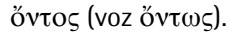


precisamente por esto que Hegel se opone radicalmente a la idea de que todos pueden filosofar sin necesidad de aprender previamente unos contenidos que, en este caso, sería la misma historia de la filosofía:

Se concede que para fabricar un zapato es necesario haber aprendido a hacerlo y, por mucho que todo el mundo tenga la horma en su propio pie, se ha de haber ejercitado en ello, ha de tener además manos y, juntamente con ellas, el talento natural para dedicarse a tal ocupación. Sólo para filosofar sería superfluo estudiar, aprender y esforzarse. Esta cómoda opinión se ha visto reforzada últimamente por la doctrina del saber inmediato o saber por intuición. (Hegel, 2017, §5)

En síntesis, la filosofía debe considerarse ciencia para que su estudio pueda ser tomado como riguroso y estricto. Por esto, es necesario desarrollar un sistema que logre dar cuenta de esa rigurosidad que exige todo sistema científico y, dado que para Hegel la filosofía es una metaciencia, ese sistema debe tener un carácter universalista, enciclopédico: un Sistema de la ciencia. Puesto que toda ciencia y todo proyecto enciclopédico tienen de base siempre un conjunto de contenidos ya desarrollados previamente (Background); la filosofía no puede ser reducida al simple filosofar, sino que el contenido más el ejercicio especulativo (filosofar) son los que permiten que la filosofía sea tomada como ciencia y no como un ejercicio trivial de una conversación de café o un bar'.

\subsection{Respuesta a la concepción fenoménica de Kant: la realidad como Wirklichkeit}

A diferencia de sus predecesores (principalmente Kant), Hegel procura salirse de la linealidad con que la gnoseología relacionaba al hombre con el mundo. Hegel reconoce que al momento de conocer algún objeto en-sí ya se supone de manera implícita un grado de reconocimiento de sí mismo como conciencia que conoce:

6 Curiosamente, algo similar concluye Confucio (1975 [Lún Yǔ]) en sus Analectas: "[...] si estudiáis sin esforzaros comprender, no obtendréis ningún fruto de vuestro estudio; si, por el contrario, abandonáis el estudio para entregaros a vuestros pensamientos, corréis el peligro de graves desviaciones" (ii, § 15). 
Característico de Hegel es la idea de que el conocimiento no es representación por un sujeto de algo "externo"; la representación por un sujeto de un objeto es a la vez parte integrante del objeto. La conciencia es no sólo conciencia del objeto, sino también conciencia de sí. Él objeto no es, pues, ni algo "exterior" ni tampoco simple contenido de conciencia. En otros términos, el conocimiento como marcha hacia lo Absoluto requiere una dialéctica del sujeto y del objeto y nunca la reducción del uno al otro. [Énfasis, fuera del original](Ferrater Mora, 1975, p. 812)

Kant (2011) encontró problemas para establecer los principios para la justificación de la cosa en-sí (noúmeno [vooú porque encontraba en el análisis de los posibles argumentos a favor de dicha postura elementos contradictorios (antinomias) provenientes de la razón pura (A406/B433; A408/B435). Dado que no podemos conocer las cosas en sí mismas, sino tan solo las representaciones que tenemos de ellas, el dualismo sujeto-objeto es algo insuperable. Hegel, por otra parte, procura solucionar dicho problema modificando la lógica misma desde la cual se ha estado operando, proponiendo una lógica dialéctica (el método) que involucre la totalidad de las concepciones y no solo la positiva (afirmativa [el en-sí]) que Kant y sus antecesores habían desarrollado (Kreines, 2006, pp. 469-475). Por otra parte, soluciona este clásico dualismo (sujeto-objeto) sobre la realidad resignificando el concepto de "realidad".

Podría decirse sin vacilar que este es el mayor aporte de Hegel: "Lo que es real [wirklich] es racional, lo que es racional es real [wirklich]" (2010c, p. 21). De esta afirmación pareciera que Hegel nos está indicando que ser real y ser racional son una misma cosa; empero, esto no es lo que indican estas proposiciones. ¿Qué quieren indicar? Que hay una relación de identidad coextensional entre lo racional y lo real, pero de esto no se sigue que "ser real" y "ser racional" sean predicados iguales intensionalmente. Si intentáramos formalizar esta cita, resultaría algo como esto: $\forall x \forall y[(\mathrm{R} x \rightarrow \mathrm{E} x) \wedge(\mathrm{E} y \rightarrow \mathrm{R} y)] \rightarrow(x \leftrightarrow y)^{7}$. Como podemos ver en la formalización, la tesis de Hegel afirma que todo lo racional es real y viceversa, pero de esto no se sigue que "ser real" y "ser racional" sean lo mismo, sino que ambos remiten a los mismos objetos, pero de manera distinta. Es decir, no hay algo que sea real y no sea racional y algo que sea racional y no sea real $(x \leftrightarrow y)$. Así, pues, para entender esta tesis es necesario

7 Sean Rx: $x$ es racional y Ex: $x$ es real. Léase: "Para todo $x$, si ese $x$ es racional, entonces es real; $y$ para todo $y$, si ese $y$ es real, entonces es racional. Luego, $x$ si, y solo si, $y$ ". 
descomponerla en sus dos partes principales: todo lo racional es real y todo lo real es racional.

En primera instancia, que todo lo racional es real no parece generar problemas. A menos que alguien tomase una postura nominalista extrema como la de Ockham (1994, I, c. 44) — según la cual los conceptos universales no añaden nada a la realidad-, generalmente es aceptado que lo racional, por ficticio que sea, también tiene un grado de realidad. Quizás la mejor respuesta a esta postura nominalista la ofrece el mismo René Descartes (2014):

Porque en verdad, ni siquiera los mismos pintores cuando tratan de inventar Sirenas y Sátiros con las formas más inusitadas, pueden asignarles naturalezas totalmente nuevas, sino que únicamente se entremezclan miembros de diversos animales; y si tal vez inventan algo tan nuevo que nada semejante haya sido visto, y que sea así por completo ficticio y falso, es cierto, sin embargo, que al menos los colores con los cuales aquello se compone deben ser verdaderos. (AT, VII, 19-20)

Así, suponiendo que algo pensado pudiese exceder lo que se da en la existencia, de ello no se sigue que no tenga algún grado de realidad, sino que precisamente esto ya constituye cierta realidad al siempre partir de la existencia misma para luego rebasarla por medio de composiciones nuevas de la imaginación. Más aún, yendo más lejos, lo racional siempre será real por el hecho de que el pensamiento siempre está ligado al yo, como bien lo demostró Fichte $(2013, \S 1)$; y, dado que la existencia del yo es una verdad necesaria (Descartes, 2014, AT, VII, 25), toda idea, concepto o representación que tenga ese yo debe siempre tener cierto grado de realidad. Así, pues, es necesario decir que todo lo racional es real.

Por otra parte, que “todo lo real es racional” es quizás el aspecto más difícil de aceptar para diversos autores. ¿Hegel quiere decir que los entes necesitan que sean pensados para que puedan existir, tal como lo aseveraba Berkeley (1995, $\$ \$ 3$ y 87)? En realidad, no. La solución de Hegel es más compleja: el clásico problema de la realidad (la correspondencia mente-mundo) ha sido abordado por los filósofos modernos a modo de anfibología. ¿Qué significa esto? Que, gracias a la tradición medieval, realidad se ha entendido como existencia y, por esto, al decir que todo lo real es racional es común asociar esta proposición con todo lo existente es racional. Empero, para Hegel, 
realidad (Wirklichkeit) es distinto de existencia. Es esta la razón de la anfibología: hay dos definiciones de realidad y su uso indiferenciado es lo que ha generado ambigüedad y pseudoproblemas.

Realidad se dice de dos maneras en alemán: como "existencia" (Realität) y como "verdad efectiva" (Wirklichkeit). Para Hegel, el uso correcto de "lo real" debería reservarse principalmente a la segunda acepción, mientras que para la segunda acepción debería preferirse el uso de existencia (Existenz) o ser determinado (Dasein). Pero ¿qué es la realidad efectiva para Hegel? Dice él:

La realidad efectiva es la unidad devenida inmediata de la esencia y la ExIsTENCIA, o de lo interior y lo exterior. La exteriorización de lo real efectivo es lo real efectivo mismo de un modo tal que, en su exteriorización, sigue siendo igualmente esencial y sólo es esencial en la misma medida en que se encuentra en la EXISTENCIA exterior inmediata. (Hegel, 2017, \$142)

¿Qué quiere decir esto? Que la realidad se distingue de la existencia en cuanto logra rebasarle y contenerle. La realidad no solo parte de la existencia, sino que también tiene en cuenta el sentido (fenómeno, dice él) que hacemos de esta. Realicemos un experimento mental: $x$ camina diario a su trabajo y por su camino se encuentra un objeto $y$, solo que $x$ nunca se había percatado de la existencia de $y$. Un día, $x$ se percata de la existencia de $y$ y gracias a esto $x$ logra percibirlo, lo piensa, le otorga un nombre - digamos, árbol-y con ese nombre logra establecer relaciones gramaticales en oraciones con sentido o proferir juicios verdaderos. Además, $x$ tiene representaciones del árbol, logra crear arte con dichas representaciones y logra a partir del lenguaje provocar representaciones similares en sus congéneres a partir de las descripciones que $x$ hace de $y$ (el árbol). Por último, $x$ en cierto punto logra desprenderse de las representaciones de $y$ cuando al ver más objetos con características similares a $y$ logra elaborar el concepto árbol. En este punto, $x$ ha logrado el máximo conocimiento que la experiencia con $y$ le podía proporcionar: el concepto mismo de árbol $(\exists y:(\mathrm{A} y))$.

Todo el proceso anteriormente descrito constituye lo que Hegel llama realidad efectiva. Ciertamente, $y$ no necesitaba que $x$ lo concibiera y nombrara árbol para existir; su existencia era ya algo puesto, algo ya determinado previamente; era Dasein ${ }^{8}$ (Hegel,

8 Este concepto es acuñado por Hegel para explicar cómo por medio de las relaciones entre el ser y la nada se genera el devenir, es decir, el "ser determinado" (Dasein). Determinado no debe entenderse aquí 
2011, 45 y ss.). Que lo real sea racional implica que hay un carácter de racionalidad en la cosa misma, mas no en la existencia de los entes. La existencia es de facto, es decir, ya está presupuesta. La realidad efectiva, por otra parte, se genera cuando hay una consciencia -o, mejor, un espíritu- que le dota sentido a esa existencia y la apropia por medio de representaciones y $\operatorname{conceptos}^{9}$. ¿Qué quiere decir esto en el tema de discusión? Que "la cosa en sí” sí tiene un carácter de racionalidad.

Recordemos que Kant justifica su principio sobre el noúmeno a partir del reconocimiento de límites en la razón pura: “[...] Los fenómenos no son cosas en sí mismas, sino el mero juego de nuestras representaciones, que finalmente vienen a parar en determinaciones del sentido interno" (Kant, 2011, A101). Pues bien, Hegel tiene en cuenta ese concepto de límite para justificar lo siguiente: lo finito debe estar contenido en lo infinito; pues, de no ser así, lo finito estaría por fuera de lo infinito, y, en ese orden de ideas, lograría rebasarle (lo cual es absurdo por la definición misma de infinito) (Hegel, 2011, 79). Luego, la relación entre lo finito y lo infinito debe ser de pertenencia $(F x \in I x)$. En ese orden de ideas, ambos se determinan entre sí $(\leftrightarrow)$ : lo finito a lo infinito en tanto que lo instancia y especifica en un algo específico, delimitado ( $\exists x$ : $(\mathrm{F} x \wedge \mathrm{I} x)$; lo infinito a lo finito, en tanto que lo contiene $y$, por esto, se manifiesta esencialmente en lo finito $(\forall x(\mathrm{~F} x \rightarrow \mathrm{I} x))$, puesto que, como ya se dijo, lo finito pertenece a lo infinito.

Si lo finito está contenido en lo infinito, este primero posee la esencia del segundo y, por lo mismo, el concepto que se posee del ser en-sí (el noúmeno) ya posee, al menos alguna parte, correspondencia y pertenencia; puesto en otros términos: en el fenómeno hay pertenencia (limitada) del noúmeno. Con esto se termina pues el problema inicial: la realidad misma no es más que el conocimiento efectivo que se da por la determinación racional del espíritu sobre el ser determinado (Dasein) y sus posibles determinaciones racionales (Hegel, 2017, § 82). En este orden de ideas, ciertamente,

como "carente de libertad", sino como aquello que llamaban los medievales materia signata (Aquino, 1963, c. 3). Ser determinado significa aquel tipo de existencia que es esta y no otra. Es decir, tiene ya configuradas ciertas leyes físicas, cualidades, extensiones, dimensiones, etc. Hegel utiliza este término para diferenciarlo del puro ser, es decir, del esse qua esse que, al ser absolutamente indiferenciado e indeterminado, es vacuo de contenido lógico (de ahí que afirme que con base en esa vacuidad "el puro ser y la pura nada son una misma cosa"). El ser determinado, por otra parte (la existencia) indica que es este ser con estas y estas cualidades; es ser-ahi (Dasein).

9 Es importante recalcar que esta idea tuvo importante eco en Husserl: "Toda realidad [Wirklichkeit] existe por obra de un 'dar sentido'" (Husserl, 2013, § 55. Igual sucede con Zubiri (1995), quien realiza las distinciones entre "realidad de suyo" (existencia) y "realidad de mío" (realidad, en sentido propio). 
los fenómenos no son las cosas mismas, pero sí son ellos en sí mismos cosas. Más aún, es gracias a la síntesis entre los fenómenos y la existencia que se constituye la realidad y, así, la verdad como la correspondencia entre ambos. Por esto, es irrelevante la pregunta por la realidad en sí misma o la verdad como algo intrínseco e inalcanzable por el hombre. La realidad es, pues, racional en tanto es el sentido que le damos a la existencia por medio del fenómeno y del concepto. "Lo que es real puede ser comprendido satisfactoriamente por el pensamiento; así como el pensamiento pertenece al mundo del que la autoconsciencia hace parte" (Burbidge, 1999, p. A101). Luego, tenemos ya afirmados los dos condicionales: todo lo racional es real y todo lo real es racional: $\forall x \forall y[(\mathrm{R} x \rightarrow \mathrm{E} x) \wedge(\mathrm{E} y \rightarrow \mathrm{R} y)] \rightarrow(x \leftrightarrow y)$.

\section{3. ¿Qué es el Absoluto?}

En el Sistema de la ciencia Hegel pretende retomar la metafísica ${ }^{10}$ como fundamento

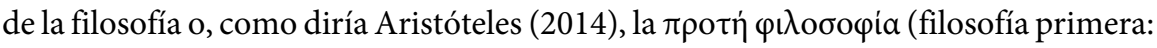
Metafísica) ( $\Gamma, 1003 a 20-33)$ (Giusti, 1994, pp. 49-53). Para hablar sobre la realidad es necesario validarla primero ontológicamente; y esta no se puede limitar en lo finito: debe pretender ir más allá de la simple certeza sensorial por medio de la reflexión que la razón dé sobre de sí misma y del mundo en que está inmersa (Hegel, 2010a). Por esto, Hegel reconoce que la misión de la filosofía - y, en especial, de la metafísica- es el estudio de lo absoluto, ya que es este el fundamento ontológico de la realidad misma: el todo en su conjunto (es decir, la síntesis) es la razón de ser de las partes, así como también las partes constituyen al todo y son el substrato último al cual se puede llegar de este todo. Por esto, el fin de su metafísica consiste en investigar al absoluto, no solo como resultado, sino también como síntesis, como proceso (Aufhenbung).

Absoluto es un concepto clave en la filosofía de Hegel. Absoluto es un constructo latino entre $a b$ y solvere, donde solvere significa "liberar, ser independiente, disolver, apartar" [voz solvo] (Lewis, Short \& Freund, 1956) y la preposición $a b$ se usa

10 Hay que aclarar que para Hegel la metafisica no ha de entenderse como un estudio de lo trascendente, sino, en término último, el estudio de las ideas que, como sintesis, refiere a la esencia (leyes, principios, $\lambda$ ó́yos) de las cosas por medio de las representaciones que tenemos de ella; de ahi que coincida con la lógica especulativa o lógica de conceptos (cfr. Hegel, 2017, §§ 9, 24; pp. 26-36). Este idealismo no es solipsista, puesto que reconoce que el concepto tiene un compromiso y estatuto ontológico (como ley natural o como referente mental); sin embargo, tras las criticas kantianas, tampoco persigue a la esencia de las cosas sin tener en cuenta que solo podemos acceder a ellas por medio de nuestros propios conceptos (Álvarez, 1982, pp. 40-42). 
para remarcar el énfasis de tal independencia. Absoluto, en este orden de ideas, es lo independiente, aquello que es por sí mismo ( $\kappa \theta^{\prime}$ aủंó), o, lo que es sin más; es decir, es lo universal, abarcativo y completo. El Absoluto, según Ferrater Mora (1975), “[...] ha sido ha sido identificado con 'lo separado o desligado de cualquier otra cosa' [...]. La expresión 'lo Absoluto' se ha opuesto, pues, con frecuencia a las expresiones 'lo dependiente', 'lo condicionado', 'lo relativo'” [voz absoluto] (p. 33). Empero, la definición de Hegel es distinta: el absoluto es el horizonte de la totalidad que no es distinto de lo relativo o particular, sino que lo particular es contenido y superado por lo universal.

En su ideal sistemático, Hegel pretende el horizonte de la totalidad. En ese horizonte la consciencia se completa en un saber absoluto; es "[...] ese nuevo horizonte donde sujeto y objeto han llegado a identificarse. Porque mientras esa dualidad subsista, resulta imposible lograr absoluta certeza sobre la adecuación del saber a su objeto" (Díaz, 1998, pp. 195-196). No obstante, Hegel no ve esa totalidad como algo distanciado del ser humano y de la existencia; es decir, como algo absolutamente independiente y distinto de lo relativo, de lo dependiente. Dice él:

Cuando el pensamiento permanece en la universalidad de las ideas (como ocurre necesariamente en las primeras filosofías, p. e. en el caso del ser de la escuela eleática, o del devenir de Heráclito, etc.) se le reprocha justificadamente su formalismo, y puede suceder incluso que filosofías más desarrolladas capten solamente los principios o determinaciones abstractas y, al tratar de lo particular, repitan monótonamente lo mismo. [...] Respecto de la primera universalidad abstracta del pensamiento, tiene un sentido auténtico fundamental decir que el desarrollo [Entwicklung] de la filosofía hay que agradecerlo a la experiencia. $(2017, \$ 12)$

Generalmente se ha asociado la idea de que el absoluto en Hegel es Dios; empero, su sentido es más amplio. Mientras en la definición clásica se asocia a Dios la condición de absoluto por ser algo independiente, libre, incondicionado, etc., en contraposición al ente o criatura (que es dependiente, relativa, etc.), Hegel asume al absoluto como espíritu; es decir, como la totalidad de lo humano que es capaz de salir de sí y unificarse con los otros y con el mundo para realizar una síntesis omniabarcante de todas las relaciones del espíritu consigo mismo y con lo otro. En este orden de ideas, el espíritu se desarrolla como absoluto cuando ha superado todos sus posibles límites 
y ha alcanzado todas sus determinaciones ${ }^{11}$ (Bestimmungen) posibles; en este estado ha alcanzado su completud, es espíritu absoluto.

En la concepción tradicional del absoluto como Dios trascendente hay una radical diferenciación de este respecto a la criatura (Aquinatis, 1951, p. [sT], I, q. 3, a. 8, sol). Dentro de esta concepción, él no pertenece a ningún género (I, q. 3, a. 7), es simple (Aquinatis, 1951, p. 120), es el Uno (Plotino, 2011, capítulo vi, sección 1, 9). Así, Dios es, como diría Leibniz, una protomónada cuya potencia es infinita e ilimitada y su acto creador solo es limitado por la receptividad de dicho acto, es decir, por la esencia limitada de la criatura (Leibniz, 1982, $\$ 48$ ). En síntesis, esta perspectiva trascendente de Dios se caracteriza por ser radicalmente dualista: hay un inmenso (absoluto) vacío entre Dios y el hombre ${ }^{12}$.

Por otra parte, Hegel rompe esta clásica dualidad y esto se puede evidenciar por dos vías: (1) Hegel se propone elevar al hombre (entendido como espíritu colectivo) al máximo grado de realidad por medio de la reflexión. Así lo explica Díaz (1998): "En otras palabras, cuando se piensa en el contexto del proceso en el cual consiste la totalidad, y aquello que se piensa es comprendido como momento de ese único proceso, se está en la verdad" (p. 188). Así, para Hegel, la realidad (entendida como la identidad sujeto-objeto) se alcanza por las sucesivas reflexiones que la razón hace sobre sí misma y las otras conciencias (en sí, para otro), sobre el mundo (para sí) y de todo junto (también llamado, espíritu absoluto). Esta elevación del espíritu humano a tan altos umbrales Díaz (1998) la denomina: "La suplantación definitiva del Dios trascendente" (p. 204).

11 Otro concepto clave en Hegel es el de determinación. Inicialmente, este concepto es utilizado para referirse a la existencia en tanto es esta y no otra. Posteriormente, con este concepto se quiere dar cuenta de las sucesivas o posibles afirmaciones que hace el objeto sobre el sujeto (y viceversa), del sujeto sobre sí mismo y los demás sujetos (y viceversa) y de la sintesis de todo lo anterior. Este concepto tiene un carácter similar al de signación usado por los medievales para referirse a las formas substanciales y se aleja de la concepción clásica de determinado como lo opuesto a libre en el debate clásico referido a la existencia o no de un destino del mundo y de las personas.

12 Si bien Hegel tiene en cuenta esta tradición; en especial, a la teoria tomista (Silveira y Rosa, 2015, pp. 6-15), es importante recalcar que el plano en el que se posiciona Hegel es el de un idealismo absoluto que parte de una concepción trascendental de la realidad. La ruptura de este dualismo, como veremos a continuación, es ejemplo de ello. Esto, como lo indica Ferreiro (2012), se puede evidenciar en sus objeciones a los contrargumentos de Kant sobre la posibilidad de demostrar la existencia de Dios. 
Por otra parte, también está la transformación del concepto de Dios como absoluto viviente, encarnado (Biblia de Jerusalem, Jn., 1:14) y que muere por el hombre. Así, el Absoluto es humanizado, es real y, por esto - antes que se concebido como un motor inmóvil- para Hegel, él está en constante devenir. Así, tampoco el Absoluto es algo inalcanzable ni absolutamente estático, sino que es perpetuamente cambiante y se le puede alcanzar por medio de la reflexión racional:

No hay en Hegel ninguna idea eterna de la Divinidad, de la Naturaleza ni del espíritu, ninguna noción estable del Derecho; todo está en perpetuo flujo y reflujo, como en la doctrina de Heráclito. Sólo una cosa permanece: el movimiento mismo; es decir, la fuerza, que es el movimiento in potentia. (Zozaya, 1915, p. 17)

Tal vez, sintetizando ambas lecturas, la solución podría ser: tanto en la elevación del espíritu al Absoluto como en la encarnación y humanización de Dios parece alcanzarse un nivel de identidad entre el espíritu y Dios. Quizás, vale recordar esta cita de Boecio: "Y a la manera en que el justo llega a serlo por la adquisición de la justicia y el sabio lo es porque adquirió la sabiduría, el que alcanza la divinidad se convierte en Dios” (Boecio, 1973, capítulo III, prosa 10,\$24). ¿Que Dios sea humanizado y alcanzable por el hombre quiere decir que él es el hombre mismo? No. Hegel no comete el error de reducir la infinitud de Dios, pues, como se mencionó anteriormente, él reconoce la distinción intensional (pero no extensional) de lo infinito respecto de lo finito; es decir, claramente, Hegel no sostiene que Dios sea finito. Lo que Hegel sostiene es que esa finitud del hombre se puede superar por medio de la razón, y es gracias a ella que se puede establecer ese puente entre Dios y el hombre. Dice Hegel (2017):

Así, el conocimiento de Dios, como de todo suprasensible, en general, contiene esencialmente una elevación sobre la aprehensión sensible o intuición; contiene, por consiguiente, una relación negativa respecto a ésta; pero en dicha relación se da juntamente la mediación. $(\$ 12)$

Como el Absoluto es Dios, la realidad tiene una significación racional (puesto que el absoluto es la totalidad de la síntesis entre lo real y lo racional como determinación superada); corresponde al $\lambda$ ó $o c$, al más alto nivel de abstracción de lo otro como lo propio. La idea se exterioriza; lo mismo [Self] busca salir de sí y volverse lo otro: la 
naturaleza es expresión de lo divino. Hegel entiende lo absoluto como la idea, que es en Platón lo universal (2013) y en Kant (2011) lo incondicionado:

El espíritu absoluto es identidad, que es en tanto eternamente en sí, cuanto debe tornar y es tornada en sí; es la única y universal sustancia como sustancia espiritual; la división (el juicio) en sí y en un saber, para el cual ella es como la substancia. (Hegel, 2017, \$554)

Ahora bien, el Absoluto se presenta en dos niveles ónticos (Jiménez, 2009, p. 84): la naturaleza y el espíritu. Ambos no son consistentes ontológicamente; en especial, no lo es la naturaleza ${ }^{13}$, pues esta es la expresión más primigenia del devenir (Hegel, 2017, $\$ \$$ 247-251). Es el infinito conteniendo a lo finito en su devenir constante. Dado que la naturaleza permanece en un constante y perfecto devenir, ella es manifestación del Absoluto. Esta idea está, probablemente, influenciada por la idea de Heráclito (1981) de que el $\Lambda$ ó $о$ oৎ (logos) es el principio ordenador de los contrarios (Heráclito, DK, 22 A 8; B 1, 2, etc.).

Por otra parte, la razón es la facultad que le permite al hombre alejarse de sí para estudiarse y conocerse; es gracias a esta que se puede pensar al hombre como espíritu: "La razón es espíritu en cuanto que la certeza de ser toda realidad está elevada a la verdad, y ella es consciente de sí misma en cuanto que es su mundo, y consciente del mundo en cuanto que es ella" (Hegel, 2010a, 238). Como se dijo en un inicio, la pretensión de Hegel es analizar cómo el espíritu humano llega a ser todo lo que su potencia le permite: el espíritu absoluto. Así, pues, podemos concluir la respuesta a la pregunta de este acápite así: el Absoluto puede entenderse en dos sentidos complementarios. Primero, como Dios en tanto ser autosuficiente y perfecto; y, segundo, como la relación entre este Dios con su criatura: o bien como manifestación del orden dialéctico en la naturaleza, o bien como la identidad que se da entre el espíritu colectivo humano con Dios a partir de la reflexión racional. En este orden de ideas, el estudio del absoluto es trascendental: es el estudio de la síntesis entre lo finito e infinito a partir de la idea. Se estudia lo ilimitado a partir de los principios o manifestaciones que este realiza parcialmente en lo limitado (Hernández y Baracaldo, 2018, p. 340, n. 15).

13 La explicación de esto la da Hegel en la "Doctrina del ser" de la Ciencia de la lógica. El argumento radica en que Hegel reconoce que la causa de que haya un ser determinado (Dasein) está en el devenir que se produce entre el ser y la nada por la determinación que genera la segunda sobre la primera (2011, 45 y ss.). 


\section{El método}

Ahora bien, Hegel concibe él método como "la forma como el absoluto se construye" (Díaz, 2015). Es preciso aclarar en este punto que el pensamiento, según su criterio, debe ser lógico; o sea, debe encadenarse un conjunto de conceptos en su vida orgánica, que no se imponga ante la naturaleza y quiera acomodarla a esta, sino mirarla desde su modo de ser; es decir, no debe estatizarla, sino que el concepto debe lograr capturar esa dialecticidad propia de la naturaleza (Hegel, 2011). Por ello, la lógica de Hegel no es formalista, sino ontológica. Por ello, para él es lícita la identidad $A=\sim \mathrm{A}^{14}$, ya que es

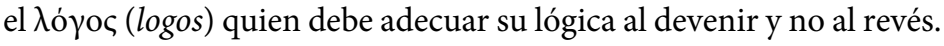

\subsection{El método: la concepción de Hegel de la dialéctica}

Hegel, a pesar de concordar con Heráclito en la idea de devenir, hace algunas altera-

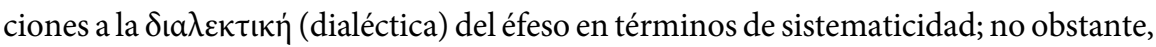
al igual que este (Heráclito), Hegel considera que la tensión no se da entre el ser con el ser mismo (puesto que lógicamente sería una imposible), sino que la tensión es entre el ser y el no ser (la nada) (Hegel, 2011, p. 45): "La unidad del ser y la nada están en devenir" (Díaz, 2015). Además, el devenir debe tener unos determinados momentos: una afirmación (ser), una negación (la nada como determinación superada de la afirmación) y una afirmación de la afirmación y la negación (devenir), pero que no se toma como un estado de resuelto, sino de movimiento en-sí y para-sí en búsqueda de totalidad dinámica (el Absoluto).

\subsection{El devenir constante y sus momentos}

A diferencia del sistema kantiano, el sistema hegeliano sí reconoce que "la realidad no es consistente ontológicamente, es decir, está en constante devenir” (Díaz, 2015).

14 Si bien Hegel (2011) sostiene de manera explicita esa violación al principio de no contradicción (p. 265), una posible salida a esta contradicción podria darse sustituyendo la relación de identidad por una de bicondicionalidad modal; es decir, de identidad extensional modal, mas no intensional. La tesis que Hegel intenta defender es que las cosas y conceptos solo son posibles a partir de su contrario. Por ejemplo, la dialéctica en los conceptos se evidencia en que todo juicio siempre afirma algo ("la mesa es blancan $[\exists x:(M x \wedge B x)])$ y a la vez niega su opuesto (la mesa no es gris, ni azul... [ $\exists x:(M x \wedge \sim G x) \vee A x \ldots .]$.$) .$ En ese orden de ideas, todo predicado es posible si y solo si es posible su contrario: $\triangle P \leftrightarrow \Delta \sim P$. Es decir, el significado de todo concepto solo es posible a partir de su contrario. Esta tesis, por ejemplo, también fue defendida poco tiempo después por Peirce (1992, EP1, p. 7), en el cual Hegel tuvo una considerable influencia metodológica y conceptual (Stern, 2009, pp. 209-344). 
Como el ser y el no-ser están en constante contraposición y, además, el hombre hace parte de ese ser (y a la vez lo transforma), el espíritu es a su vez reflejo y elemento constituyente de la realidad. Reuniendo lo anterior, se reafirma el aforismo clave de su filosofía: "Lo que es real [wirklich] es racional, lo que es racional es real [wirklich]" $(2017, \$ 6)$. El hombre, al ser sujeto racional, es el único capaz de alcanzar los tres grados del conocimiento o del desarrollo del espíritu (Geist) por medio de la afirmación de sí (Self) hacia el único saber que abarca la totalidad: el Absoluto.

El método (la dialéctica) se presenta tanto en el conjunto del sistema como en cada uno de los peldaños que este posee. Esto tiene una explicación: es el devenir mismo. Son tres los momentos a tener en cuenta en la dialéctica. (1) El en-sí, o sea: una fijación de una determinación, una afirmación de sí. (2) La negación de esa determinación como autodeterminación, es el momento de alteración; es nihilista-corrosivo y, además, involucra a lo afirmado en su esencia negativa. Y (3) el conocimiento racional superador (Aufhenbung) que hace un despliegue de estos dos anteriores en un reencuentro como la unidad superior: el Absoluto en devenir. En gran medida, lo anteriormente mencionado es una especie de refracción respecto al sistema; es el cómo se comporta este último. Por esto, al igual que como en el sistema, cada parte tiene su razón de ser. En el método cada momento debe ser claro y tiene un significado propio.

\subsection{Los momentos del espíritu}

En Hegel, el espíritu se supera (Aufhenbung) en tres momentos: la determinación del propio pensamiento, la filosofía de la naturaleza y la filosofía del espíritu (Hegel, $W d L$, I, 265).

El primer momento es el del pensamiento (espíritu subjetivo [en-sí]); es la constitución básica donde el espíritu se afirma en tanto que es. Para avanzar en este punto, presenta su propia constitución dialéctica: ser, esencia y concepto. Inicialmente, el ser se me presenta en tanto que es. Yo, en mi necesidad de conocer al “ser en tanto que ser" (esse

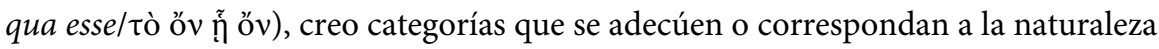
dialéctica de este; no obstante, estas categorías entran en conflicto en su relación con la realidad dialéctica de las cosas — crítica que Hegel le hace a Kant-. Ahí se presentan las esencialidades de la reflexión, y como síntesis de estas dos “fases” surge la unión y superación de estas dos: el concepto propio. 
El segundo momento es la filosofía de la naturaleza (espíritu objetivo [para-sí]), la exteriorización de la idea: lo "siempre mismo" busca salir de sí y volverse lo otro. Es el concepto la alienación de la idea. La naturaleza no se piensa a sí misma (a diferencia de la filosofía de Schelling [2005]); solo se nos presenta para que el espíritu pueda desarrollarse y preguntarse cómo se forma el tiempo, el espacio, los cuerpos, etc.; en otras palabras: la vida. Este viene a ser precisamente su límite.

El tercer momento es la filosofía del espíritu (espíritu absoluto [en-sí y para-sí]). El hombre reconoce su constitución en la historia, su ser. En este orden de ideas, logra reconocerse, no solo como individuo, sino también como colectivo; como una consciencia colectiva en tanto que este (el individuo) es el resultado de las determinaciones de la sociedad en él —sobre todo, por medio de la educación-y de él sobre sí mismo. Además, este reconocimiento no solo es sobre el estado actual, sino como todo un proceso de desarrollo activo que se sintetiza en ese estado presente.

Lo único que se hace patente en la historia universal es el modo progresivo como el espíritu universal llega a una consciencia y a una voluntad de verdad. Al comienzo, ambas no hacen en él más que alborear; el espíritu consigue, luego, momentos importantes, para alcanzar, al fin, la plenitud de consciencia. (Hegel, 2010b, p. 367)

En síntesis, cada momento constituye en sí una manifestación del método dialéctico y todos los momentos sintetizados constituyen otro método mayor, y así sucesivamente hasta llegar al Absoluto. En las explicaciones tradicionales se suele reducir el método dialéctico a una simple relación espiral lineal entre tesis, antítesis y síntesis (que, de hecho, pertenece más al sistema de Fichte, 2013; no de Hegel), que es graficada así (véase esquema 1): 
Esquema 1. Relación lineal atribuida a la dialéctica hegeliana.

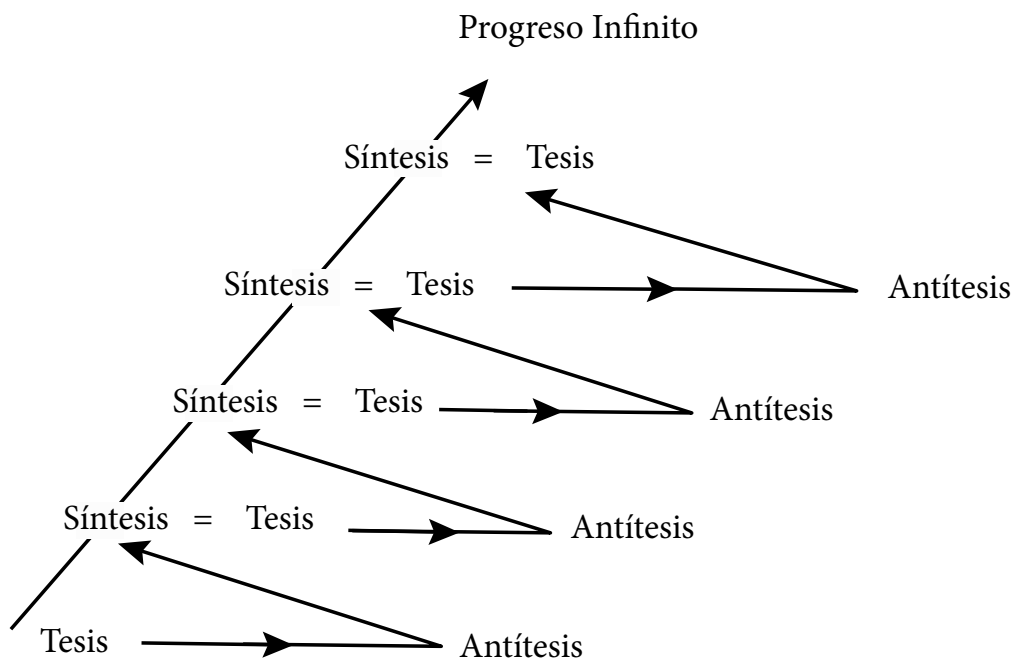

Fuente: Arendt, H. (1984). La vida del espíritu (p. 306). Barcelona: Paidós.

Ahora bien, la relación entre los momentos parece ser más compleja que esto. ¿Por qué? Porque los momentos no son independientes entre sí, sino que ambos se relacionan bicondicionalmente $(\mathrm{P} \leftrightarrow \sim \mathrm{P})$, porque, como se dijo anteriormente, para Hegel todos los elementos (del método y el sistema) son en sí mismos, pero también en cuanto se relacionan con los demás. No hay ningún elemento aislado o independiente de los demás, aunque sí es posible pensarlos por sí mismos como un punto de partida. Dado que hay una relación de bicondicionalidad entre los elementos, la relación entre los momentos es necesaria. Esto implica que también la relación bicondicional entre el todo y la parte sea necesaria, lo que lleva Hegel a proponer una relación de momentos que constituyen momentos más grandes con las mismas cualidades metódicas $([(\Phi \rightarrow \Psi) \wedge(\Psi \rightarrow \Phi)] \rightarrow(\Phi \leftrightarrow \Psi))$. Así lo explica Leisegang, en palabras de Ferrater Mora (1975):

Cada serie de tríadas dialécticas puede considerarse como encerrada en un círculo. Este círculo, con su triada dialéctica, se combina con otros dos círculos de otras tantas tríadas dialécticas para formar parte de otro círculo, el cual se combina con otros dos conteniendo otras tantas tríadas dialécticas. [voz perifilosofía] (p. 398) 
Esta interpretación parece ser la más adecuada para expresar dicha dialéctica. Empero, valdría aclarar que las tríadas no constituirían tres círculos, sino que el tercer momento (la síntesis) sería la intersección entre ambos. A partir del siguiente gráfico (véase esquema 2) puede explicar, grosso modo, dicha dialéctica incorporando la relación bicondicional ya explicada:

Esquema 2. Sistema y métodos integrados dialécticamente por teoría de conjuntos.

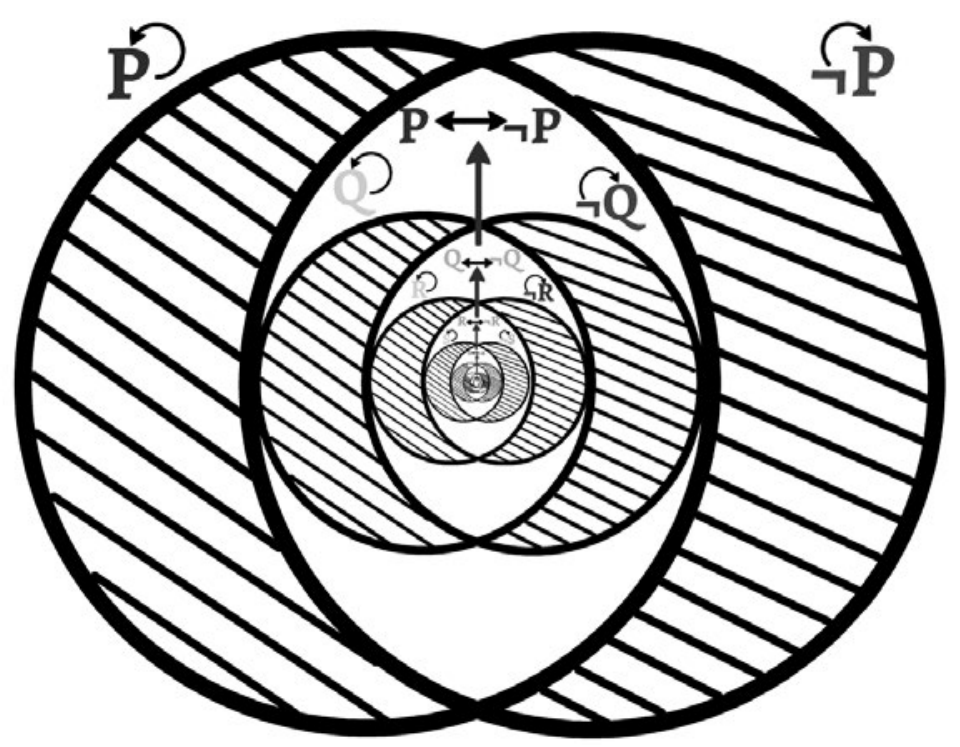

Fuente: elaboración propia.

Así, la relación lógica entre los contrarios estaría más cercana de esta formalización:

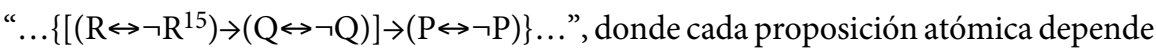
de sí misma $(\mathrm{P} \rightarrow \mathrm{P}) \wedge(\neg \mathrm{P} \rightarrow \neg \mathrm{P})$ (el "en-sí" y "para-sí"). Posteriormente, ambos conjuntos unidos constituirían un momento (cada uno tético por sí y antitético del otro) y la proposición molecular sería la síntesis de las dos anteriores, que, a su vez, podría

15 Téngase en cuenta que cada relación bicondicional representa, a su vez, a uno de los típicos dualismos de la metafísica clásica (sujeto-existencia, realidad-existencia, real-aparente, etc.). Además, cada concepto afirmativo o negativo $(\mathrm{P} / \sim \mathrm{P})$ es, a su vez sintesis de representaciones, experiencias 0 percepciones; o bien, de otros conceptos. La línea gris representa la ascesis o superación (Aufhenbung) de una sintesis (o bicondicionalidad) a otra. 
considerarse como una nueva proposición atómica de una molecular más grande, y así sucesivamente. Todavía más, cada síntesis $\left(v \cdot g r\right.$. ‘ $^{\mathrm{Q}} \leftrightarrow \neg \mathrm{Q}$ ') ${ }^{16}$ está contenida en la intersección entre las dos fórmulas atómicas $(\mathrm{P} \cap \neg \mathrm{P})$, donde la diferencia entre ambos conjuntos es vacía: . El reto del método (las flechas verticales) consiste, pues, en lograr transitar desde la esfera (intersección) más pequeña (la existencia, como síntesis del puro ser y la pura nada) hasta la más amplia (el Absoluto) por medio de la reflexión de la razón. El tránsito de una esfera menor a una mayor es lo que Hegel denomina Aufhenbung (compensación o superación de la dualidad). De esta manera, pues, se relacionan sistema y método por medio de la dialéctica, entendida como la ascesis de una relación bicondicional a otra más abarcativa.

\section{Conclusión}

Una vez expuesto el sistema y el método surge la pregunta: ¿qué aporta todo esto a la filosofía? La respuesta derivada de la anterior exposición es: una visión de hombre completa en tanto que es - bien sea en su aspecto natural como espiritual — en disposición de sí mismo. Hegel tenía en cuenta que lo que iba a hacer era una filosofía descriptiva del hombre en cuanto tal (recordemos que él ve la filosofía como ciencia del espíritu).

Es bien conocido hoy día que muchos autores le han criticado y que dichas críticas no son insensatas del todo, pero es preciso exigirles algunos matices: a las políticas (1) y estéticas (2), como se remarcó en la exposición del sistema, se le exige que para Hegel ningún elemento puede explicarse sin el otro; ambos se explican y son en virtud de su contraparte. Igual sucede con la relación individuo-Estado o naturalezaarte. Del hecho de que se tome a uno u otro como partida no se sigue que no sean necesarios; más aún, la superación no ha de entenderse como una relación lineal (como si $\neg$ P superara a P), sino de elevación de un bicondicional a otro. A la crítica histórica (3), ciertamente, se le admite que esos rasgos sí se encuentran en el sistema de Hegel (como en muchos modernos). Quizás, la falta de conocimiento y las pocas

16 Es preciso recordar aqui que ' $\mathrm{P} \leftrightarrow \neg \mathrm{P}$ ' no implica necesariamente una violación al principio de no contradicción, pues, como lo indica Aristóteles (2014): "Es imposible que lo mismo se dé y no se dé a la vez en el mismo sentido" [las cursivas son mías] ( $\Gamma, 1005 b 19-20)$. En primer lugar, ' $\mathrm{P} \rightarrow \neg \mathrm{P}^{\prime} \mathrm{y} \mathrm{A}^{\prime} \mathrm{P} \rightarrow \mathrm{P}^{\prime}$ son sentidos distintos, como se ve en los ejemplos. En segundo, ' $\forall x(\mathrm{P} x \leftrightarrow \neg P x)$ ' no es equivalente a $' \exists x:(\mathrm{P} x \wedge \neg \mathrm{P} x)$ ' porque la primera proposición molecular no tiene compromiso existencial; además, la relación entre ' $P x^{\prime} y^{\prime} \neg P x^{\prime}$ puede ser sencillamente hipotética y traducible en términos modales ' $\forall x(\Delta P x \leftrightarrow \Delta \neg P x)$ ', donde, efectivamente, no hay contradicción alguna. 
traducciones de los textos orientales y de los códices fueran un factor de ello. Al menos así lo afirma Tola (2010) en relación a la filosofía de la India (p. 82). A la crítica antropológica (4), verdaderamente, se le reconoce el racionalismo de Hegel puede sonar a muchos algo exagerado, pero no lo es tanto si tenemos en cuenta que razón (Vernunft) no es reducible para Hegel a intelecto (Verstand/voũ $)$ ). Que lo afectivo sea racional no implica que todo sea lógico o formalizable, sino que se dice que es racionalidad en virtud de una relación dialéctica de afirmación del mundo sobre esa consciencia ( $x$ me causa temor) y de una consciencia de sí mismo (yo siento temor). Y a la lógico-epistemológica (analítica) (5), indiscutiblemente, se le concede que defender una teoría sustentada en contradicciones suena para muchos - me incluyo también- en una imprudencia formal. Empero, hay que tener en cuenta dos cosas: (1) Si Hegel intenta sostener una postura dialéctica no es por su interés en violar la lógica formal, sino porque para él es primordial el poder de la lógica para expresar la naturaleza. Las reglas puramente formales niegan, ocultan y privan a las teorías de poder expresar las múltiples relaciones entre los elementos por enfocarse en uno solo (como sucedía con Kant al reducir la relación sujeto-objeto a un cuasi solipsismo). Y (2) si se intentan comprender ese afán de Hegel y cuál era la razón por la cual se vio abocado a defender tal postura, es posible ver que dichas preocupaciones se pueden solventar fácilmente con una modificación de ' $\mathrm{P}=\neg \mathrm{P}$ ' por ' $\diamond \mathrm{P} \leftrightarrow \diamond \neg \mathrm{P}$ ', y el sentido de la obra de Hegel sería el mismo sin necesidad de violar el principio de no contradicción. Claro está, los avances en la lógica no eran para su época tantos como los actuales y es muy probable que ello lo llevara a tener una mala valoración de su obra, sistema y método (algo muy común en la historia de la filosofía). Es evidente que todas estas respuestas no están en las obras de Hegel de manera explícita, pero sí es cierto que una vez decantados esos errores, a partir de las herramientas que nos proporcionan los estudios contemporáneos podríamos rescatar dicho sistema y proyecto para depurarlo de esas imperfecciones.

Ahora bien, decir que el sistema no tiene vigencia es precisamente una contradicción con la realidad, pues: (1) esa urgencia de criticar y citar a Hegel por parte de los filósofos analíticos y continentales denota la importancia y vigencia misma de su filosofía; y (2) es Hegel precisamente quien rompe con la forma tradicional de ver y hacer filosofía: abre el paso al pensamiento contemporáneo al resignificar el concepto de realidad como algo semántico y no simplemente ontológico, y al introducir el valor de la historia como elemento esencial del pensamiento y desarrollo humano. 
Aunque se reconoce que el sistema no es perfecto y puede tener sus fallas formales (como, por ejemplo, fundamentarse en la contradicción como principio lógico y metafísico), también debe reconocerse que este sistema sí es punto de reflexión y crítica constante para que otros sistemas filosóficos puedan surgir y evitar errores pasados; como dice Jacques D’Hondt (2002): “Hegel no deja de resucitar. No será fácil abarcarlo del todo. Un hombre no se encierra para siempre en un dibujo, en un relato en una tumba. Hegel lo sabía más que nadie. En sus imágenes lo dio a entender" (p. 382).

\section{Referencias}

Adorno, T. W. (1983). Teoría estética (Fernando Riaza, trad.). Barcelona: Orbis.

Aquinatis, T. (1951). Summa theologioe. Pars I. MADRID: BAC.

Aquino de, T. (1963). El ente y la esencia (Manuel Fuentes Benot, trad.). Buenos Aires: Aguilar.

Arendt, H. (1984). La vida del espíritu (R. Montoro y F. Vallespin, trad.). Barcelona: Paidós.

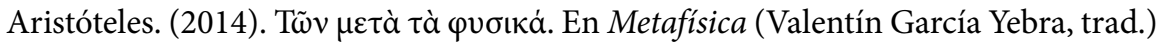
(pp.1-790). Madrid: Gredos.

Berkeley, G. (1995). Tratado sobre los principios del conocimiento humano (Carlos Mellizo, trad.). Barcelona: Altaya.

Boecio. (1973). La consolación de la filosofía (Pablo Masa, trad.). Buenos Aires: Aguilar.

Burbidge, J. (1999). Hegel's conception of logic. En F. C. Beiser (ed.), The Cambridge Companion to Hegel (pp. 86-101). Cambridge: Cambridge University Press.

Carnap, R. (2009). La superación de la metafísica por medio del análisis lógico del lenguaje (Nicolás Molina, trad.). México, D. F.: UNAM.

Descartes, R. (2014). Meditaciones acerca de la Filosofía Primera (Jorge Aurelio Díaz, trad.) (1ª ed.). Bogotá: Universidad Nacional de Colombia.

D’Hont, J. (2002). Hegel (Carlos Pujol, trad.). Buenos Aires: Tusquets. 
Díaz, J. A. (1998). La concepción metafísica de Hegel. En J. Gracia, Concepciones de la metafísica (pp. 187-208). Madrid: Trotta.

Díaz, J. A. (27 de abril de 2015). Movimiento reflexivo del deseo de reconocimiento: una interpretación de la independencia o sujeción de la autoconciencia. Hegel y la Fenomenología del Espíritu.

Ferrater Mora, J. (1975). Diccionario de filosofía Tomos 1 y 2. Buenos Aires: Sudamericana.

Ferreiro, H. (2012). El argumento ontológico y la muerte de la metafísica: dos visiones complementarias - Kant y Hegel. Veritas, 57(3), 99-120. Recuperado de: https:// philarchive.org/archive/FEREAO

Fichte, J. G. (2013). Fundamentos de toda la doctrina de la ciencia. En F. Oncina Coves (ed.), Obra completa. Madrid: Gredos.

Giusti, M. (1994). Raíces metafísicas de la Lógica de Hegel. Areté, 6(1), 49-59. Recuperado de http://revistas.pucp.edu.pe/index.php/arete/article/view/5140

Hegel, G. W. F. (2010a). Fenomenología del espíritu (Antonio Gómez Ramos, trad). Madrid: Abada.

Hegel, G. W. F. (2010b). Lecciones de la filosofía de la historia (Josep María Quintana, trad). En V. Rühle (ed.), Obras completas 2: Líneas fundamentales de la filosofía del derecho. Lecciones de la filosofía de la historia. Madrid: Gredos.

Hegel, G. W. F. (2010c). Líneas fundamentales de la filosofía del derecho ( $\mathrm{M}^{\mathrm{a}} \mathrm{del}$ Carmen Paredes, trad.). En V. Rühle (ed.), Obras completas 2: Líneas fundamentales de la filosofía del derecho. Lecciones de la filosofía de la historia. Madrid: Gredos.

Hegel, G. W. F. (2011). Ciencia de la lógica. Tomo 1 (Félix Duque, trad.). Madrid: Abada.

Hegel, G. W. F. (2013). Ciencia de la lógica (Augusta Algranati y Rodolfo Mondolfo, trads.). Buenos Aires: Editorial Las Cuarenta.

Hegel, G. W. F. (2017). Enciclopedia de las ciencias filosóficas (Ramón Vals Plana, trad.). Madrid: Abada. 
Heidegger, M. (2014). ¿Qué es la metafísica? (Helena Cortés y Arturo Leyte, trads.). Madrid: Alianza.

Heráclito. (1981). Testimonios y fragmentos. En C. Eggers Lan y V. E. Juliá (eds.), Los filósofos presocráticos. Tomos 1, 2 y 3 (pp. 211-150). Madrid: Gredos.

Hernández, J. C. y Baracaldo, C. A. (2018). Antecedentes metafísicos del concepto ser de Sartre. Universitas philosophica, 35(71), 323-349. DoI: 10.11144/Javeriana. uph35-71.amss

Hernández, J. C. y Pérez, J. (2018). Choque de paradigmas: análisis a las prohibiciones de Tamburini y Retz a diversas tesis modernas. Cuadernos de Filosofía Latinoamericana, 39(119), 47-76. DoI: http://www.doi.org/10.15332/25005375.5050

Husserl, E. (2013). Ideas relativas a una fenomenología pura y una filosofía fenomenológica I: Idea general a la fenomenología pura. Tomo I (José Gaos, trad.). México, D. F.: Fondo de Cultura Económica.

Hylton, P. (1999). Hegel and analytic philosophy. En F. C. Beiser (ed.), The Cambridge Companion to Hegel (pp. 445-487). Cambridge: Cambridge University Press.

Jiménez Redondo, M. (2009). Introducción. En G. W. F. Hegel, Fenomenología del espíritu (Manuel Jiménez Redondo, trad.). Valencia: Pre-Textos.

Kant, I. (2011). Crítica de la razón pura (Mario Caimi, trad.). México, D. F.: Fondo de la Cultura Económica.

Kreines, J. (2006). Hegel's Metaphysics: Changing the Debate. Philosophy Compass, 1(5). 466-480. DOI: 10.1111/j.1747-9991.2006.00033.x

Lewis C. T., Short, C. y Freund, W. (1956). Latin Dictionary by Lewis \& Short, Founded on Andrew's Edition of Freund's Latin Dictionary. Oxford: Oxford University Press. Recuperdado de: http://www.perseus.tufts.edu/hopper/text?doc=Perseus\%3Atex t\%3A1999.04.0059\%3Aentry\%3Drevisio

Lydell, H. G. y Scott, R. (1996). Greek-English Lexicon. Clarendon: Oxford University Press. Recuperado de: http://www.perseus.tufts.edu/hopper/resolveform? redirect $=$ true 
Marx, K. (2012). Textos selectos: Textos de filosofía, política y economía. Manuscritos de París. Manifiesto del Partido Comunista. Crítica del programa de Gotha. Madrid: Gredos.

Nietzsche, F. (2006). La voluntad de poder (Aníbal Broufe, trad.). Madrid: EDAF.

Ockham de, G. (1994). Suma de lógica (Alfonso Flórez Flórez, trad.). Bogotá: Norma.

Peirce, C. S. (1992) The Essential Peirce: Selected Philosophical Writtings. Volume 1 (1867-1893).N. Houser y C. Kloesel (eds.), Bloomington: Indiana University Press.

Platón. (2013). Sofista. En Diálogos: Critón. Gorgias. Menón. Fedro. Sofista. Político. Cartas. Madrid: Centro de Estudios Políticos y Constitucionales.

Plotino. (2011). Enéadas (Jesús Igal, trad.). Madrid: Gredos.

Rühle, V. (2010). G.W. F. Hegel, la transformación de la metafísica. Em V. Rühle (ed.), Obras completas 1 (pp. XI-CXVIII). Madrid: Gredos.

Russell, B. (1964). La sabiduría de Occidente (Juan García Puente, trad.). Buenos Aires: Aguilar.

Russell, B. (1966). Sobre la denotación (Javier Muguerza, trad.). En Ensayos sobre lógica y conocimiento (1901-1950) (pp. 51-74). Madrid: Taurus.

Schelling von, F. W. J. (2005). Sistema del idealismo trascendental (Jacinto Rivera de Rosales y Virginia López, trads.). Madrid: Anthropos.

Schopenhauer, A. (2016). El mundo como voluntad y representación (Roberto R. Aramayo, trad.). México, D. F.: Fondo de Cultura Económica.

Silveira da, C. F. y Rosa da, T. (2015). Metafísica e ideia - a originalidade da concepção tomista em confronto com Spinoza e Hegel. Synesis, 7(2), 1-17. Recuperado de: https://dialnet.unirioja.es/descarga/articulo/6356679.pdf

Stern, R. (2009). Hegelian Metaphysics. Oxford: Oxford University Press.

Suares, P. (2011). The Kyoto School's Takeover of Hegel: Nishida, Nishitani and Tanabe Remake the Philosophy of Spirit. United Kingdom: Lexington Books.

Tola, F. y Dragonneti, C. (2010). La filosofía de la India. Barcelona: Kairós. 
Waibl, E., y Herdina, P. (1997). Wörtebuch philosophischer Fachbegriffe Englisch. Münschen: K. G. Saur Verlag.

Zozaya, A. (1915). La guerra de las ideas. Madrid: Sociedad general española de librería diarios, revistas y publicaciones, S. A.

Zubirí, X. (1995). Estructura dinámica de la realidad. Madrid: Alianza. 


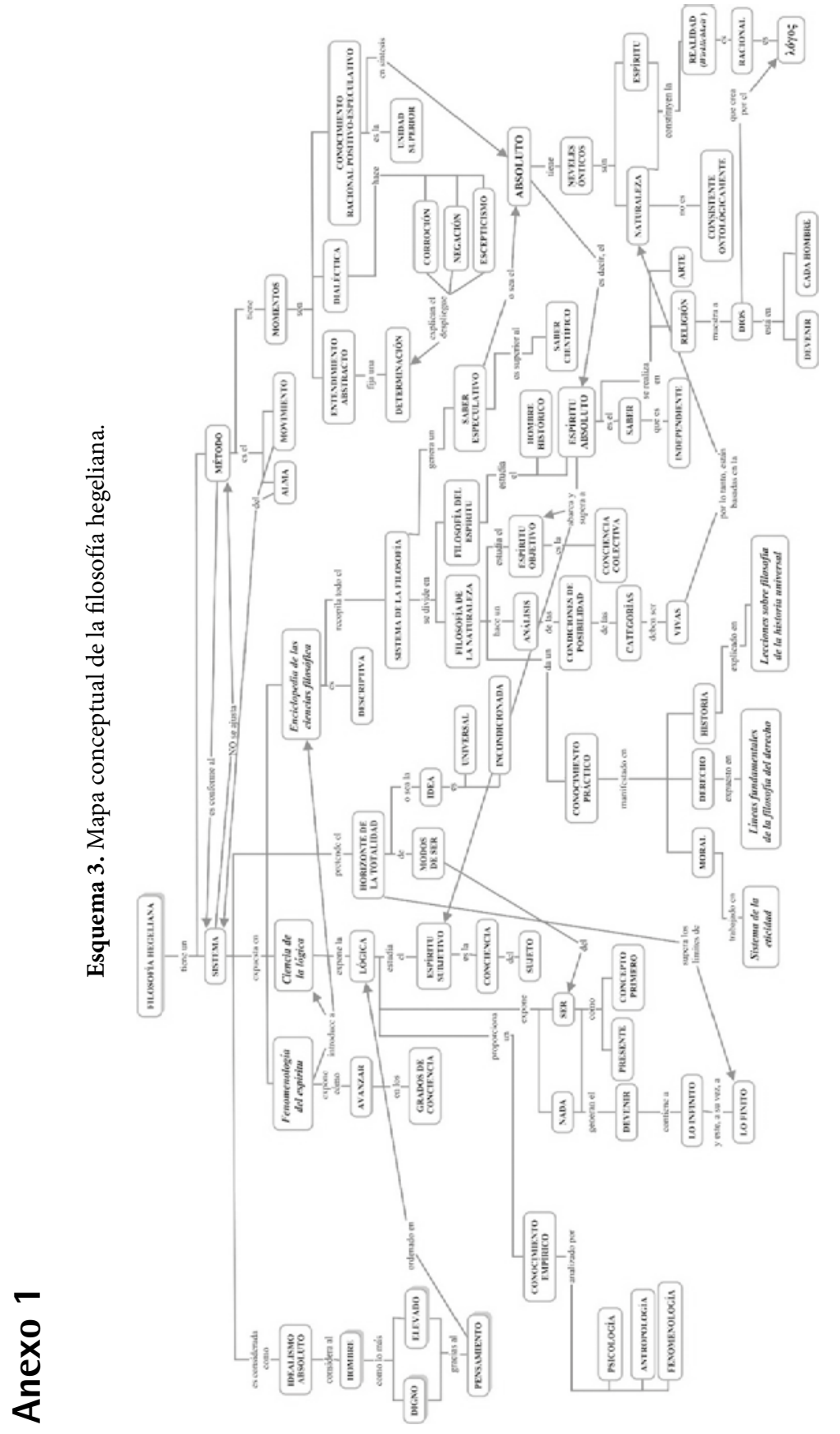

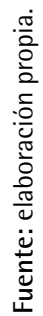

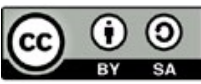

